\title{
Perturbation and age-related changes in the fatty acid pattern of soleus muscle phospholipids and triglycerides in rats depleted in long-chain polyunsaturated $\omega 3$ fatty acids
}

\author{
WILLY J. MALAISSE ${ }^{1}$, LAURENCE PORTOIS ${ }^{2}$, ABDULLAH SENER $^{1}$ and YVON A. CARPENTIER ${ }^{2}$ \\ Laboratories of ${ }^{1}$ Experimental Hormonology and ${ }^{2}$ Surgery, Brussels Free University, B-1070 Brussels, Belgium
}

Received August 1, 2007; Accepted September 10, 2007

\begin{abstract}
Altered D-glucose metabolism prevails in the soleus muscle of rats depleted in long-chain polyunsaturated $\omega 3$ fatty acids $(\omega 3)$. In these animals, the prior intravenous injection of an $\omega 3$-rich medium-chain triglyceride:fish oil emulsion ( $\omega 3-\mathrm{FO}$ rats), as compared to that of an $\omega 3$-poor medium-chain triglyceride:olive oil emulsion ( $\omega 3-\mathrm{OO}$ rats), may either correct or aggravate selected metabolic variables. This study deals with the fatty acid pattern of soleus phospholipids and triglycerides in control animals versus $\omega 3-$ depleted rats not injected with any lipid emulsion ( $\omega 3-\mathrm{NI}$ rats) and in $\omega 3-\mathrm{OO}$ versus $\omega 3-\mathrm{FO}$ rats. In each group of $\omega 3$ depleted rats, age-related changes were also monitored. The $\omega 3$-depleted rats displayed low long-chain polyunsaturated $\omega 3$ fatty acid content, facilitated metabolism of long-chain polyunsaturated $\omega 6$ fatty acids, and increased $\Delta 9$-desaturase activity. Both the age-related changes in lipid variables and those attributable to the prior intravenous injection of the 133 rich lipid emulsion consisted either in a move towards normalization or in the opposite direction, i.e. towards aggravation of the defect found in the 13 -depleted rats. Emphasis is placed, therefore, on the unusual situation found in the soleus muscle of $\omega 3$-depleted rats, in which both lipid and metabolic variables may be either favourably or adversely affected by the same environmental factor(s).
\end{abstract}

\section{Introduction}

In a recent study, conducted in the framework of investigations dealing with the metabolic, hormonal and functional perturbations, found in second generation rats depleted in long-chain polyunsaturated $\omega 3$ fatty acids (1-6), differences were found between these rats and control animals in terms of D-glucose metabolism in stretched soleus muscles

Correspondence to: Professor Willy J. Malaisse, Laboratory of Experimental Hormonology, Brussels Free University, 808 Route de Lennik, B-1070 Brussels, Belgium

E-mail: malaisse@ulb.ac.be

Key words: long-chain polyunsaturated $\omega 3$ fatty acid-depleted rats, soleus muscle, phospholipid and triglyceride fatty acid pattern incubated in vitro in the absence or presence of insulin (1). In this prior study, advantage was also taken from the bolus intravenous administration to the $\omega 3$-depleted rats $60-120$ min before sacrifice of an $\omega 3$ fatty acid-rich medium-chain triglyceride:fish oil emulsion (MCT:FO), as compared to an $\omega 3$ fatty acid-poor medium-chain triglyceride:olive oil emulsion (MCT:OO), to assess rapid changes in muscle metabolic variables possibly resulting from the enrichment of phospholipids in long-chain polyunsaturated $\omega 3$ fatty acids, as achieved under these experimental conditions in several cell types $(1,3,4)$.

The present study concerns a comparison between uninjected $\omega 3$-depleted rats and control animals, as well as between $\omega 3$-depleted rats injected intravenously with either the MCT:FO or MCT:OO emulsion, in terms of the fatty acid content and pattern of soleus muscle phospholipids and triglycerides. Moreover, the possible occurrence of agerelated changes in these lipid variables in non-injected $\omega 3$ depleted rats $(\omega 3-\mathrm{NI})$ and those injected with the MCT:FO ( $\omega 3-\mathrm{FO})$ or MCT:OO ( $\omega 3-\mathrm{OO})$ emulsion were examined in animals of increasing age (8-9, 15-16, and 22-23 weeks). The results of the present study thus provide three sets of information. First, it documents vast differences between $\omega 3-\mathrm{NI}$ rats and control animals. Second, it reveals age-related changes in the $\omega 3$-depleted rats. Last, it indicates, as already observed for the metabolism of D-glucose in the soleus muscle, that the prior injection of the MCT:FO emulsion may either move selected variables towards the values otherwise found in control animals or, on the contrary, accentuate the anomaly otherwise observed in $\omega 3$-NI or $\omega 3$-OO rats.

\section{Materials and methods}

Sixteen female normal rats and 78 female second generation w3-depleted rats were given free access to either a control diet or an $\omega 3$-depleted diet, up to the time of sacrifice. Each of three groups of $\omega 3$-depleted rats (18 $\omega 3$-NI, $30 \omega 3-\mathrm{OO}$ and $30 \omega 3-\mathrm{FO})$ consisted of equal numbers of rats with increasing ages (8-9, 15-16 and 22-23 weeks), so that the overall mean age of these $\omega 3$-depleted rats was similar to that of the control animals. The $\omega 3-\mathrm{OO}$ and $\omega 3-\mathrm{FO}$ rats were injected intravenously, 60-120 min before sacrifice, with $1.0 \mathrm{ml}$ of either the MCT:OO or MCT:FO emulsion. The composition of the diets given to the control and $\omega 3$-depleted rats, as well 
Table I. Phospholipid fatty acid content and pattern in control and $\omega 3-$ NI rats.

\begin{tabular}{|c|c|c|c|c|}
\hline & \multicolumn{4}{|c|}{ Rats (age in weeks) } \\
\hline & Control & $\omega 3-\mathrm{NI}(8-9)$ & $\omega 3-N I(15-16)$ & $\omega 3-\mathrm{NI}(22-23)$ \\
\hline Total content (mg/g) & $10.41 \pm 0.32(16)$ & $8.85 \pm 0.22(6)$ & $8.95 \pm 0.21(6)$ & $9.03 \pm 0.25(6)$ \\
\hline C16:0 (\%) & $13.2 \pm 0.2(16)$ & $15.9 \pm 0.2(6)$ & $16.1 \pm 0.4(6)$ & $15.3 \pm 0.1(6)$ \\
\hline $\mathrm{C} 16: 1 \omega 7(\%)$ & $0.1 \pm 0.0(16)$ & $0.4 \pm 0.0(6)$ & $0.5 \pm 0.0(6)$ & $0.5 \pm 0.0(6)$ \\
\hline C18:0 (\%) & $15.6 \pm 0.1(16)$ & $18.9 \pm 0.1(6)$ & $17.8 \pm 0.4(6)$ & $17.8 \pm 0.2(6)$ \\
\hline $\mathrm{C} 18: 1 \omega 9(\%)$ & $3.2 \pm 0.1(16)$ & $5.2 \pm 0.1(6)$ & $5.1 \pm 0.1(6)$ & $5.2 \pm 0.1(6)$ \\
\hline $\mathrm{C} 18: 2 \omega 6(\%)$ & $19.6 \pm 0.4(16)$ & $25.4 \pm 0.2(6)$ & $25.2 \pm 0.8(6)$ & $25.5 \pm 0.5(6)$ \\
\hline $\mathrm{C} 18: 3 \omega 3(\%)$ & $0.3 \pm 0.0(16)$ & $0.0 \pm 0.0(6)$ & $0.0 \pm 0.0(6)$ & $0.0 \pm 0.0(6)$ \\
\hline 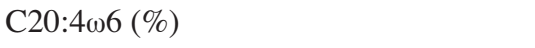 & $18.7 \pm 0.3(16)$ & $28.6 \pm 0.2(6)$ & $28.8 \pm 0.6(6)$ & $29.1 \pm 0.5(6)$ \\
\hline $\mathrm{C} 20: 5 \omega 3(\%)$ & $0.3 \pm 0.0(16)$ & $0.0 \pm 0.0(6)$ & $0.0 \pm 0.0(6)$ & $0.0 \pm 0.0(6)$ \\
\hline 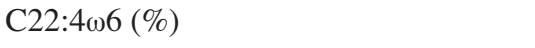 & $0.7 \pm 0.0(16)$ & $2.6 \pm 0.1(6)$ & $2.3 \pm 0.1(6)$ & $2.2 \pm 0.0(6)$ \\
\hline $\mathrm{C} 22: 5 \omega 3(\%)$ & $3.3 \pm 0.1(16)$ & $0.3 \pm 0.0(6)$ & $0.4 \pm 0.0(6)$ & $0.5 \pm 0.0(6)$ \\
\hline 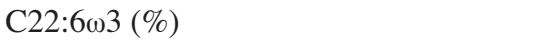 & $23.5 \pm 0.4(16)$ & $1.2 \pm 0.1(6)$ & $1.9 \pm 0.1(6)$ & $2.1 \pm 0.1(6)$ \\
\hline $\mathrm{C} 16: 1 \omega 7 / \mathrm{C} 16: 0\left(\mathrm{x} 10^{3}\right)$ & $12.6 \pm 0.5(13)$ & $24.0 \pm 2.2(6)$ & $30.3 \pm 1.5(6)$ & $29.3 \pm 1.5(6)$ \\
\hline $\mathrm{C} 18: 1 \omega 9 / \mathrm{C} 18: 0$ & $0.202 \pm 0.005(16)$ & $0.276 \pm 0.007(6)$ & $0.289 \pm 0.011(6)$ & $0.293 \pm 0.006(6)$ \\
\hline$(\mathrm{C} 18: 0+\mathrm{C} 18: 1 \omega 9) /(\mathrm{C} 16: 0+\mathrm{C} 16: 1 \omega 7)$ & $1.41 \pm 0.02(16)$ & $1.48 \pm 0.03(6)$ & $1.40 \pm 0.05(6)$ & $1.46 \pm 0.02(6)$ \\
\hline $\mathrm{C} 20: 4 \omega 6 / \mathrm{C} 18: 2 \omega 6$ & $0.96 \pm 0.03(16)$ & $1.13 \pm 0.02(6)$ & $1.15 \pm 0.06(6)$ & $1.15 \pm 0.04(6)$ \\
\hline 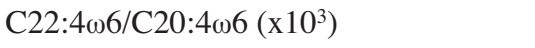 & $36.1 \pm 1.0(16)$ & $89.2 \pm 3.5(6)$ & $79.5 \pm 2.6(6)$ & $73.9 \pm 1.0(6)$ \\
\hline $\mathrm{C} 22: 6 \omega 3 / \mathrm{C} 22: 5 \omega 3$ & $7.23 \pm 0.23(16)$ & $3.82 \pm 0.17(6)$ & $4.74 \pm 0.16(6)$ & $4.66 \pm 0.32(6)$ \\
\hline
\end{tabular}

as that of the two lipid emulsions were previously provided (4). Likewise, the method used to measure the phospholipid and triglyceride fatty acid content and the pattern in extracts from the soleus muscle was described in a prior publication (7).

The metabolic and hormonal status of the rats used in the present study was reported in a recent publication (8).

For the sake of simplicity, the fatty acids listed in the Tables were restricted to those considered in the Results section.

All results were presented as mean values ( \pm SEM), together with the number of individual observations (n). The statistical significance of differences between mean values was assessed by use of the Student's t-test or, whenever so required, by covariance analysis.

\section{Results}

Phospholipids. The results of the measurements made in soleus muscle phospholipids are summarized in Tables I and II.

The total fatty acid content was lower $(\mathrm{p}<0.001)$ in $\omega 3-\mathrm{NI}$ rats $(8.94 \pm 0.12 \mathrm{mg} / \mathrm{g}$ wet $w \mathrm{t} ; \mathrm{n}=18)$ than in control animals $(10.41 \pm 0.32 \mathrm{mg} / \mathrm{g} ; \mathrm{n}=16)$. In the $\omega 3$-depleted rats, it failed to display any age-related change and failed to differ significantly in $\omega 3$ - NI, $\omega 3-\mathrm{OO}(9.09 \pm 0.19 ; \mathrm{n}=30)$ and $\omega 3$-FO rats $(8.99 \pm 0.16 ; \mathrm{n}=30)$.

Long-chain polyunsaturated $\omega 3$ fatty acids. In control animals, C18:3 $\omega 3$ and $\mathrm{C} 20: 5 \omega 3$ accounted, respectively, for $0.25 \pm 0.03$ and $0.26 \pm 0.01 \%$ of the total fatty acid content of muscle phospholipids. These two $\omega 3$ fatty acids remained below the limit of detection in all $\omega 3-\mathrm{NI}(\mathrm{n}=18)$ and $\omega 3-\mathrm{OO}$ rats $(\mathrm{n}=30)$. In the $\omega 3-\mathrm{FO}$ rats, $\mathrm{C} 18: 3 \omega 3$ was also never detected, whilst $\mathrm{C} 20: 5 \omega 3(0.18 \%)$ was only found in one out of 30 animals.

The weight percentage of $\mathrm{C} 22: 5 \omega 3$ and $\mathrm{C} 22: 6 \omega 3$ was approximately ten times lower in $\omega 3$-depleted rats than in control animals. Both at 60 and at $120 \mathrm{~min}$ after injection of the lipid emulsions, the $\mathrm{C} 22: 5 \omega 3$ content of phospholipids was higher in $\omega 3-\mathrm{FO}$ than in $\omega 3-\mathrm{OO}$ rats. Pooling together the data obtained at different ages, the value found in $\omega 3-\mathrm{FO}$ rats averaged $109.7 \pm 3.7 \%(n=30 ; p<0.03)$ of the corresponding mean values recorded at the same age and same time after injection of the emulsion in $\omega 3-\mathrm{OO}$ rats $(100.0 \pm 2.1 \%$; $\mathrm{n}=30)$. No significant increase in the phospholipid C22:6w3 weight percentage was found, when comparing $\omega 3-\mathrm{FO}$ to $\omega 3-\mathrm{OO}$ rats. Nevertheless, $120 \mathrm{~min}$ after intravenous injection of the MCT:FO emulsion, the C22:6 13 phospholipid content averaged $110.0 \pm 4.8 \%(n=12 ; p<0.07)$ of the mean corresponding values found at the same age and time in $\omega 3$-OO rats $(100.0 \pm 2.1 \% ; n=12)$.

Whether in $\omega 3-\mathrm{NI}, \omega 3-\mathrm{OO}$ or $\omega 3$-FO rats, both the absolute values $(\mu \mathrm{g} / \mathrm{g}$ wet $\mathrm{wt})$ and relative values (weight percentage) of C22:5 23 and $\mathrm{C} 22: 6 \omega 3$ augmented progressively with increasing age (Table III). These findings led us to investigate whether other phospholipid variables also displayed agerelated changes in the $\omega 3$-depleted rats.

The paired $\mathrm{C} 22: 6 \omega 3 / \mathrm{C} 22: 5 \omega 3$ ratio in muscle phospholipids averaged $4.41 \pm 0.16(n=18)$ in $\omega 3-N I$ rats, $4.20 \pm 0.12$ $(n=29)$ in $\omega 3-O O$ rats and $4.17 \pm 0.18(n=30)$ in $\omega 3-F O$ rats. These mean values were not significantly different from one another and much lower $(\mathrm{p}<0.001)$ than that recorded in 
Table II. Phospholipid fatty acid content and pattern in $\omega 3-\mathrm{OO}$ and $\omega 3-\mathrm{FO}$ rats.

\begin{tabular}{|c|c|c|c|c|c|c|}
\hline & \multicolumn{6}{|c|}{ Rats (age in weeks) } \\
\hline & $\omega 3-\mathrm{OO}(8-9)$ & $\omega 3-\mathrm{OO}(15-16)$ & $\omega 3-\mathrm{OO}(22-23)$ & $\omega 3-\mathrm{FO}(8-9)$ & $\omega 3-\mathrm{FO}(15-16)$ & $\omega 3-\mathrm{FO}(22-23)$ \\
\hline Total content (mg/g) & $9.40 \pm 0.27(10)$ & $9.32 \pm 0.14(10)$ & $8.55 \pm 0.45(10)$ & $8.96 \pm 0.34(10)$ & $8.73 \pm 0.25(10)$ & $9.28 \pm 0.11(10)$ \\
\hline $\begin{array}{l}\mathrm{C} 16: 0(\%) \\
\mathrm{C} 16: 1 \omega 7(\%)\end{array}$ & $\begin{array}{r}16.8 \pm 0.4(10) \\
0.4 \pm 0.0(10)\end{array}$ & $\begin{array}{r}16.3 \pm 0.3(10) \\
0.4 \pm 0.0(10)\end{array}$ & $\begin{array}{r}15.3 \pm 0.2(10) \\
0.5 \pm 0.0(10)\end{array}$ & $\begin{array}{r}17.1 \pm 0.2(10) \\
0.5 \pm 0.0(10)\end{array}$ & $\begin{array}{r}16.7 \pm 0.2(10) \\
0.5 \pm 0.0(10)\end{array}$ & $\begin{array}{r}15.1 \pm 0.2(10) \\
0.4 \pm 0.0(10)\end{array}$ \\
\hline $\mathrm{C} 18: 0(\%)$ & $18.6 \pm 0.1(10)$ & $18.2 \pm 0.2(10)$ & $17.9 \pm 0.2(10)$ & $18.5 \pm 0.2(10)$ & $17.6 \pm 0.2(10)$ & $17.6 \pm 0.2(10)$ \\
\hline $\mathrm{C} 18: 1 \omega 9(\%)$ & $5.7 \pm 0.1(10)$ & $5.2 \pm 0.1(10)$ & $5.1 \pm 0.1(10)$ & $5.6 \pm 0.1(10)$ & $5.4 \pm 0.2(10)$ & $5.3 \pm 0.1(10)$ \\
\hline $\mathrm{C} 18: 2 \omega 6(\%)$ & $25.1 \pm 0.6(10)$ & $25.3 \pm 0.8(10)$ & $25.0 \pm 0.7(10)$ & $24.9 \pm 0.5(10)$ & $25.4 \pm 0.7(10)$ & $25.4 \pm 0.4(10)$ \\
\hline $\mathrm{C} 18: 3 \omega 3(\%)$ & $0.0 \pm 0.0(10)$ & $0.0 \pm 0.0(10)$ & $0.0 \pm 0.0(10)$ & $0.0 \pm 0.0(10)$ & $0.0 \pm 0.0(10)$ & $0.0 \pm 0.0(10)$ \\
\hline 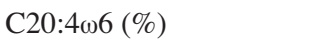 & $27.7 \pm 0.5(10)$ & $28.3 \pm 0.6(10)$ & $29.7 \pm 0.4(10)$ & $27.5 \pm 0.3(10)$ & $28.0 \pm 0.4(10)$ & $29.3 \pm 0.3(10)$ \\
\hline $\mathrm{C} 20: 5 \omega 3(\%)$ & $0.0 \pm 0.0(10)$ & $0.0 \pm 0.0(10)$ & $0.0 \pm 0.0(10)$ & $0.0 \pm 0.0(10)$ & $0.0 \pm 0.0(10)$ & $0.0 \pm 0.0(10)$ \\
\hline $\mathrm{C} 22: 4 \omega 6(\%)$ & $2.7 \pm 0.1(10)$ & $2.4 \pm 0.1(10)$ & $2.1 \pm 0.1(10)$ & $2.8 \pm 0.1(10)$ & $2.4 \pm 0.1(10)$ & $2.2 \pm 0.1(10)$ \\
\hline $\mathrm{C} 22: 5 \omega 3(\%)$ & $0.3 \pm 0.0(10)$ & $0.4 \pm 0.0(10)$ & $0.5 \pm 0.0(10)$ & $0.3 \pm 0.0(10)$ & $0.4 \pm 0.0(10)$ & $0.5 \pm 0.0(10)$ \\
\hline $\mathrm{C} 22: 6 \omega 3(\%)$ & $1.2 \pm 0.0(10)$ & $1.8 \pm 0.1(10)$ & $2.0 \pm 0.1(10)$ & $1.2 \pm 0.0(10)$ & $1.8 \pm 0.1(10)$ & $1.9 \pm 0.1(10)$ \\
\hline $\mathrm{C} 16: 1 \omega 7 / \mathrm{C} 16: 0\left(\mathrm{x} 10^{3}\right)$ & $25.2 \pm 1.3(10)$ & $25.9 \pm 1.3(10)$ & $3.02 \pm 1.2(10)$ & $27.8 \pm 1.5(10)$ & $31.0 \pm 2.2(10)$ & $29.8 \pm 1.5(10)$ \\
\hline $\mathrm{C} 18: 1 \omega 9 / \mathrm{C} 18: 0$ & $0.307 \pm 0.004(10)$ & $0.284 \pm 0.005$ & $0.288 \pm 0.005$ (10) & $0.306 \pm 0.005$ & $0.304 \pm 0.010$ & $0.304 \pm 0.009$ (10) \\
\hline $\begin{array}{l}(\mathrm{C} 18: 0+\mathrm{C} 18: 1 \omega 9) / \\
(\mathrm{C} 16: 0+\mathrm{C} 16: 1 \omega 7)\end{array}$ & $1.42 \pm 0.03(10)$ & $1.41 \pm 0.04(10)$ & $1.47 \pm 0.03(10)$ & $1.38 \pm 0.03(10)$ & $1.34 \pm 0.02(10)$ & $1.47 \pm 0.02(10)$ \\
\hline $\mathrm{C} 20: 4 \omega 6 / \mathrm{C} 18: 2 \omega 6$ & $1.12 \pm 0.04(10)$ & $1.13 \pm 0.06(10)$ & $1.20 \pm 0.05(10)$ & $1.00 \pm 0.10(10)$ & $1.12 \pm 0.05(10)$ & $1.16 \pm 0.03(10)$ \\
\hline $\mathrm{C} 22: 4 \omega 6 / \mathrm{C} 20: 4 \omega 6\left(\times 10^{3}\right)$ & $98.5 \pm 3.0(10)$ & $83.9 \pm 2.6(10)$ & $72.1 \pm 1.6(10)$ & $103.3 \pm 2.2(10)$ & $85.7 \pm 1.6(10)$ & $73.7 \pm 1.3(10)$ \\
\hline $\mathrm{C} 22: 6 \omega 3 / \mathrm{C} 22: 5 \omega 3$ & $3.66 \pm 0.12(9)$ & $4.74 \pm 0.19(10)$ & $4.14 \pm 0.17(10)$ & $3.68 \pm 0.13(10)$ & $4.79 \pm 0.31(10)$ & $4.04 \pm 0.35(10)$ \\
\hline
\end{tabular}

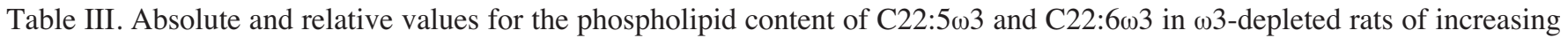
age.

\begin{tabular}{|c|c|c|c|c|}
\hline \multirow[t]{2}{*}{ Age (weeks) } & \multicolumn{2}{|c|}{ Absolute values ( $\mu \mathrm{g} / \mathrm{g}$ wet $\mathrm{wt})$} & \multicolumn{2}{|c|}{ Relative values (weight \%) } \\
\hline & $\mathrm{C} 22: 5 \omega 3$ & $\mathrm{C} 22: 6 \omega 3$ & $\mathrm{C} 22: 5 \omega 3$ & $\mathrm{C} 22: 6 \omega 3$ \\
\hline $8-9$ & $28.7 \pm 1.4(26)$ & $110.0 \pm 2.5(26)$ & $0.32 \pm 0.01(26)$ & $1.21 \pm 0.02(26)$ \\
\hline $15-16$ & $34.9 \pm 0.8(26)$ & $164.8 \pm 4.0(26)$ & $0.39 \pm 0.01(26)$ & $1.83 \pm 0.04(26)$ \\
\hline $22-23$ & $42.7 \pm 1.4(26)$ & $176.6 \pm 5.0(26)$ & $0.48 \pm 0.01(26)$ & $1.98 \pm 0.05(26)$ \\
\hline
\end{tabular}

control animals $(7.23 \pm 0.23 ; \mathrm{n}=16)$. In the $\omega 3$-depleted rats, this ratio underwent an up-and-down evolution with increasing age. Indeed, it first increased $(\mathrm{p}<0.001)$ from $3.71 \pm 0.08(\mathrm{n}=25)$ in 8 - to 9 -week-old rats to $4.76 \pm 0.14(\mathrm{n}=26)$ in 15 - to 16 week-old rats, and then decreased $(\mathrm{p}<0.02)$ to $4.22 \pm 0.17$ $(n=26)$ in 22 - to 23 -week-old $\omega 3$-depleted rats.

Long-chain polyunsaturated $\omega 6$ fatty acids. The weight percentage of the three major long-chain polyunsaturated $\omega 6$ fatty acids in muscle phospholipids, i.e. C18:2 $\omega 6, \mathrm{C} 20: 4 \omega 6$ and $\mathrm{C} 22: 4 \omega 6$, were much higher $(\mathrm{p}<0.001)$ in $\omega 3$-depleted rats than in control animals. The values recorded in $\omega 3$-NI rats $(n=18)$ and control animals $(n=16)$ averaged, respectively $25.35 \pm 0.31$ and $19.59 \pm 0.37$ in the case of $C 18: 2 \omega 6$, $28.82 \pm 0.25$ and $18.67 \pm 0.26$ in the case of $C 20: 4 \omega 6$, and $2.33 \pm 0.05$ and $0.69 \pm 0.02$ in the case of $C 22: 4 \omega 6$.

In the $\omega 3$-depleted rats, the relative contribution of C18:2 $\omega 6$ to the muscle phospholipids failed to display any

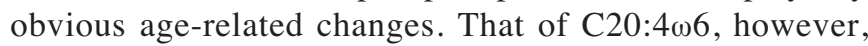

progressively increased with age $(\mathrm{p}<0.001)$. Indeed relative to the overall mean value found in the same type of $\omega 3$ depleted rats ( $\omega 3$-NI, $\omega 3-\mathrm{OO}$ or $\omega 3$-FO rats), it represented $(\mathrm{n}=26$ in all cases) $97.6 \pm 0.8,99.3 \pm 1.1$ and $103.1 \pm 0.7 \%$ at $8-9,15-16$ and 22-23 weeks of age. Inversely, the weight percentage of C22:4 $\omega 6$ progressively decreased from $2.72 \pm 0.05 \%$ in the young rats to $2.36 \pm 0.04$ and $2.15 \pm 0.03 \%$ $(\mathrm{n}=26$ in all cases; $\mathrm{p}<0.001)$ in middle-age and older animals.

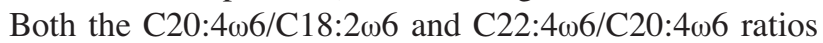
in muscle phospholipids were significantly higher $(\mathrm{p}<0.001)$ in $\omega 3$-depleted rats than in control animals, suggesting facilitated metabolism in the sequence of reactions involved in the generation of $\mathrm{C} 20: 4 \omega 6$ from $\mathrm{C} 18: 2 \omega 6$ and $\mathrm{C} 22: 4 \omega 6$ from $\mathrm{C} 20: 4 \omega 6$ in the $\omega 3$-depleted rats. The $\mathrm{C} 20: 4 \omega 6 / \mathrm{C} 18: 2 \omega 6$ and $\mathrm{C} 22: 4 \omega 6 / \mathrm{C} 20: 4 \omega 6$ ratios averaged, respectively, $1.142 \pm 0.023$ and $0.081 \pm 0.002(n=18$ in both cases) in $\omega 3-\mathrm{NI}$ rats, as distinct from $0.959 \pm 0.026$ and $0.036 \pm 0.001 \quad(n=16$ in

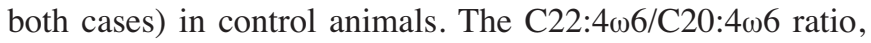
but not the $\mathrm{C} 20: 4 \omega 6 / \mathrm{C} 18: 2 \omega 6$ ratio, underwent an obvious 
age-related change in the $\omega 3$-depleted rats. Relative to the overall mean value found in each group of $\omega 3$-depleted rats ( $\omega 3-\mathrm{NI}, \omega 3-\mathrm{OO}$ and $\omega 3-\mathrm{FO}$ ), the results recorded in young, middle-age and older rats for the phospholipid C22:4 06 / C20:4 6 ratio averaged, respectively, $115.5 \pm 2.0,98.4 \pm 1.5$, and $86.1 \pm 1.1 \%$ ( $n=26$ in all cases); these three mean values being significantly different $(\mathrm{p}<0.001)$ from one another.

Relative to the mean value recorded at the same age in $\omega 3-\mathrm{OO}$ rats, the $\mathrm{C} 20: 4 \omega 6 / \mathrm{C} 18: 2 \omega 6$ ratio and the $\mathrm{C} 22: 4 \omega 6$ / $\mathrm{C} 20: 4 \omega 6$ ratio in muscle phospholipids averaged, respectively, in the $\omega 3-\mathrm{FO}$ rats $94.6 \pm 3.4$ and $103.1 \pm 1.1 \% \quad(n=30$ in both cases); these two percentages being significantly different from one another $(\mathrm{p}<0.025)$. Even when taking into account the SEM on the mean values recorded in both $\omega 3-\mathrm{OO}$ and $\omega 3-F O$ rats for these two ratios, the lowest results obtained in $\omega 3$-depleted rats injected with either the MCT-OO or MCTFO emulsion $(95.8 \pm 1.8 \% ; n=60)$ yielded a $\mathrm{p}$ value $<0.06$ when compared to the mean measurements made in 133 -depleted rats injected with the other lipid emulsion $(100.0 \pm 1.3 \%$; $\mathrm{n}=60$ ). In other words, while the injection of the MCT-FO

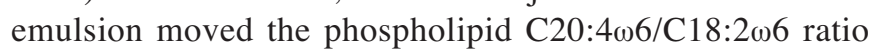

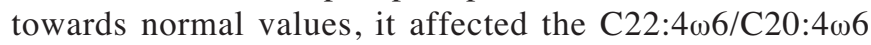
ratio in the opposite direction.

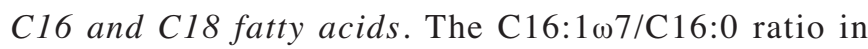
phospholipids was much higher $(\mathrm{p}<0.001)$ in $\omega 3$-depleted rats $\left(28.2 \pm 0.6 \times 10^{-3} ; \mathrm{n}=78\right)$ than in control animals $\left(12.6 \pm 0.5 \times 10^{-3} ; n=13\right)$. As a matter of fact in three control animals, no $\mathrm{C} 16: 1 \omega 7$ could be detected in the phospholipid, whilst such was never the case in $\omega 3$-depleted rats. In the latter animals, the phospholipid $\mathrm{C} 16: 1 \omega 7 / \mathrm{C} 16: 0$ ratio was significantly higher in $\omega 3-\mathrm{FO}$ than in $\omega 3-\mathrm{OO}$ rats, averaging in the former animals $109.6 \pm 3.6 \%(n=30 ; p<0.05)$ of the mean corresponding values found in $\omega 3-\mathrm{OO}$ rats of the same age $(100.0 \pm 2.6 \% ; n=30)$. In the $\omega 3$-depleted rats, the phospholipid $\mathrm{C} 16: 1 \omega 7 / \mathrm{C} 16: 0$ ratio was also related to the age of the animals. It increased ( $<<0.05$ or less) from $25.9 \pm 0.9 \times 10^{-3}(n=26)$ in the youngest animals to $28.9 \pm 1.1 \times 10^{-3}$ and $29.8 \pm 0.8 \times 10^{-3}(\mathrm{n}=26$ in both cases) in 15 - to $16-$ and 22 to 23 -week-old rats, respectively. Thus, both the difference between $\omega 3-\mathrm{OO}$ versus $\omega 3-\mathrm{FO}$ rats and the age-related increase in the phospholipid $\mathrm{C} 16: 1 \omega 7 / \mathrm{C} 16: 0$ ratio in $\omega 3$ depleted animals were in opposite direction of that otherwise expected from a normalization of this variable linked to the corresponding changes of the phospholipid content in longchain polyunsaturated $\omega 3$ fatty acids.

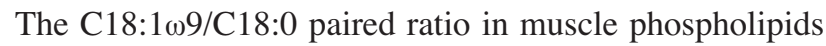
was also higher $(\mathrm{p}<0.001)$ in $\omega 3-\mathrm{NI}(0.286 \pm 0.005 ; \mathrm{n}=18)$, $\omega 3-\mathrm{OO}(0.292 \pm 0.003 ; \mathrm{n}=30)$ and $\omega 3-\mathrm{FO}$ rats $(0.305 \pm 0.005$; $\mathrm{n}=30)$ than in control animals $(0.202 \pm 0.005 ; \mathrm{n}=16)$. No significant age-related changes in this ratio were observed in the $\omega 3$-depleted rats. However, as indicated by the mean values just mentioned, the $\mathrm{C} 18: 1 \omega 9 / \mathrm{C} 18: 0$ ratio was higher $(\mathrm{p}<0.01$ or less) in the $\omega 3-\mathrm{FO}$ rats than in either the $\omega 3-\mathrm{NI}$ or $\omega 3-\mathrm{OO}$ rats; the measurements made in the latter two groups of animals being comparable to one another $(p>0.2)$. In respect to both the difference between the control and $\omega 3$ depleted rats and that between the $\omega 3-\mathrm{FO}$ and $\omega 3-\mathrm{OO}$ rats, the findings concerning the phospholipid C18:1w9/C18:0 ratio were thus similar to those recorded in the case of the phospholipid C16:1 1 7/C16:0 ratio.

Finally, the activity of elongase was judged from the $(\mathrm{C} 18: 0+\mathrm{C} 18: 1 \omega 9) /(\mathrm{C} 16: 0+\mathrm{C} 16: 1 \omega 7)$ ratio in muscle phospholipids. Such a ratio was not significantly different in the control $(1.414 \pm 0.025 ; \mathrm{n}=16)$, $\omega 3$-NI $(1.445 \pm 0.021 ; \mathrm{n}=18)$, $\omega 3-\mathrm{OO}(1.430 \pm 0.019 ; \mathrm{n}=30)$ and $\omega 3-\mathrm{FO}$ rats $(1.397 \pm 0.022$; $\mathrm{n}=30$ ). Likewise, in the $\omega 3$-depleted rats, it was little affected by the age of the animals, averaging $1.417 \pm 0.018(n=26)$ in 8- to 9-week-old rats, $1.378 \pm 0.020(\mathrm{n}=26)$ in 15 - to 16 -weekold rats and $1.468 \pm 0.014(\mathrm{n}=26)$ in 22 - to 23 -week-old rats. Only the latter mean value was slightly higher $(\mathrm{p}<0.05$ or less) than the two former ones.

Triglycerides. The data relative to the fatty acid content and pattern of muscle triglycerides are summarized in Tables IV and $\mathrm{V}$.

The total amount of triglyceride fatty acids in the soleus muscle displayed considerable individual variability. For instance, in the three groups of $\omega 3$-depleted rats ( $\omega 3-\mathrm{NI}$, $\omega 3-\mathrm{OO}$ and $\omega 3-\mathrm{FO})$, its coefficient of variation averaged $104.9 \pm 3.1 \%(n=3)$, as compared to only $9.1 \pm 1.6 \%(n=3)$ for the total fatty acid content of muscle phospholipids in the same animals. No significant difference in such a total amount of triglyceride fatty acids was found when comparing $\omega 3$-NI, $\omega 3-\mathrm{OO}$ or $\omega 3$-FO rats to control animals.

Advantage was then taken from the inverse relationship between such a total amount of triglyceride fatty acids and their relative content (percent) in $\mathrm{C} 20: 4 \omega 6$ (9) to compare the relationship between these two variables in $\omega 3$-depleted rats and control animals. The latter relationship displaying a hyperbolic pattern, the product of the neperian logarithm of the total triglyceride fatty acid content $(\mu \mathrm{g} / \mathrm{g}$ wet $\mathrm{wt})$ by the weight percentage of C20:4 $1 \omega 6$ was calculated in each rat. It averaged, in $\omega 3$-NI rats, $21.37 \pm 0.90(n=18)$ as distinct $(\mathrm{p}<0.01)$ from $25.25 \pm 1.11(\mathrm{n}=15)$ in control animals. The mean values found in the $\omega 3-\mathrm{OO}(22.69 \pm 1.16 ; \mathrm{n}=30)$ and $\omega 3$ FO rats $(20.44 \pm 0.77 ; n=30)$, which did not significantly differ from one another $(\mathrm{p}>0.1)$ or that found in $\omega 3$-NI rats, yielded an overall mean value $(21.57 \pm 0.70 ; n=60)$ also significantly lower $(\mathrm{p}<0.02)$ than that recorded in the control animals. These results document a different relationship between the total fatty acid content of muscle triglyceride and their relative content of $\mathrm{C} 20: 4 \omega 6$ in $\omega 3$-depleted rats as compared to control animals. The biological significance of this difference is considered in the Discussion section of the present report.

Long-chain polyunsaturated $\omega 3$ fatty acids. In control

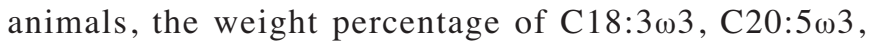
$\mathrm{C} 22: 5 \omega 3$ and $\mathrm{C} 26: \omega 3$ in muscle triglycerides represented, respectively, $3.07 \pm 0.10,0.12 \pm 0.04,1.18 \pm 0.14$ and $2.73 \pm 0.30$ $(\mathrm{n}=15$ in all cases). Only C20:5 23 remained below the limit of detection in 9 out of 15 animals. In these 15 control rats, the $\mathrm{C} 22: 6 \omega 3 / \mathrm{C} 22: 5 \omega 3$ ratio in triglycerides averaged $2.306 \pm 0.099$.

In $\omega 3$-NI rats, none of these long-chain polyunsaturated $\omega 3$ fatty acids could be detected $(n=18$ in each case). As a rule, these $\omega 3$ fatty acids also remained below the limit of detection in $\omega 3$-OO and $\omega 3$-FO rats. Only 7 out of $60 \omega 3$-depleted rats 
Table IV. Triglyceride fatty acid content and pattern in control and $\omega 3-\mathrm{NI}$ rats.

\begin{tabular}{|c|c|c|c|c|}
\hline & \multicolumn{4}{|c|}{ Rats (age in weeks) } \\
\hline & Control & $\omega 3-N I(8-9)$ & $\omega 3-N I(15-16)$ & $\omega 3-N I(22-23)$ \\
\hline Total content $(\mathrm{mg} / \mathrm{g})$ & $10.24 \pm 4.01(15)$ & $11.74 \pm 4.92(6)$ & $4.01 \pm 0.65(6)$ & $5.66 \pm 1.82(6)$ \\
\hline $\mathrm{C} 16: 0(\%)$ & $21.4 \pm 0.5(15)$ & $22.8 \pm 0.6(6)$ & $25.7 \pm 1.0(6)$ & $25.8 \pm 1.0(6)$ \\
\hline $\mathrm{C} 16: 1 \omega 7(\%)$ & $3.3 \pm 0.3(15)$ & $5.0 \pm 0.4(6)$ & $5.4 \pm 0.3(6)$ & $5.8 \pm 0.5(6)$ \\
\hline C18:0 (\%) & $3.6 \pm 0.1(15)$ & $3.1 \pm 0.3(6)$ & $3.5 \pm 0.2(6)$ & $3.6 \pm 0.3(6)$ \\
\hline $\mathrm{C} 18: 1 \omega 9(\%)$ & $20.0 \pm 0.5(15)$ & $29.5 \pm 0.5(6)$ & $27.1 \pm 0.5(6)$ & $27.6 \pm 0.5(6)$ \\
\hline $\mathrm{C} 18: 2 \omega 6(\%)$ & $39.3 \pm 0.9(15)$ & $33.8 \pm 0.8(6)$ & $31.4 \pm 0.8(6)$ & $31.9 \pm 0.8(6)$ \\
\hline $\mathrm{C} 18: 3 \omega 3(\%)$ & $3.1 \pm 0.1(15)$ & $0.0 \pm 0.0(6)$ & $0.0 \pm 0.0(6)$ & $0.0 \pm 0.0(6)$ \\
\hline $\mathrm{C} 20: 4 \omega 6(\%)$ & $2.9 \pm 0.2(15)$ & $2.1 \pm 0.3(6)$ & $2.7 \pm 0.2(6)$ & $2.8 \pm 0.2(6)$ \\
\hline $\mathrm{C} 20: 5 \omega 3(\%)$ & $0.1 \pm 0.0(15)$ & $0.0 \pm 0.0(6)$ & $0.0 \pm 0.0(6)$ & $0.0 \pm 0.0(6)$ \\
\hline $\mathrm{C} 22: 4 \omega 6(\%)$ & $0.2 \pm 0.1(15)$ & $0.2 \pm 0.1(6)$ & $0.6 \pm 0.1(6)$ & $0.2 \pm 0.1(6)$ \\
\hline $\mathrm{C} 22: 5 \omega 3(\%)$ & $1.2 \pm 0.1(15)$ & $0.0 \pm 0.0(6)$ & $0.0 \pm 0.0(6)$ & $0.0 \pm 0.0(6)$ \\
\hline $\mathrm{C} 22: 6 \omega 3(\%)$ & $2.7 \pm 0.3(15)$ & $0.0 \pm 0.0(6)$ & $0.0 \pm 0.0(6)$ & $0.0 \pm 0.0(6)$ \\
\hline $\mathrm{C} 16: 1 \omega 7 / \mathrm{C} 16: 0\left(\mathrm{x} 10^{3}\right)$ & $153 \pm 12(15)$ & $220 \pm 22(6)$ & $212 \pm 15(6)$ & $229 \pm 27(6)$ \\
\hline $\mathrm{C} 18: 1 \omega 9 / \mathrm{C} 18: 0$ & $5.7 \pm 0.3(15)$ & $10.1 \pm 1.1(6)$ & $8.0 \pm 0.6(6)$ & $8.0 \pm 1.0(6)$ \\
\hline$(\mathrm{C} 18: 0+\mathrm{C} 18: 1 \omega 9) /(\mathrm{C} 16: 0+\mathrm{C} 16: 1 \omega 7)$ & $0.96 \pm 0.02(15)$ & $1.17 \pm 0.01(6)$ & $1.39 \pm 0.05(6)$ & $1.46 \pm 0.02(6)$ \\
\hline $\mathrm{C} 20: 4 \omega 6 / \mathrm{C} 18: 2 \omega 6\left(\mathrm{x} 10^{3}\right)$ & $75.6 \pm 5.0(15)$ & $62.7 \pm 7.5(6)$ & $85.1 \pm 7.7(6)$ & $89.4 \pm 6.7(6)$ \\
\hline $\mathrm{C} 22: 4 \omega 6 / \mathrm{C} 20: 4 \omega 6\left(\mathrm{x} 10^{3}\right)$ & $167 \pm 7(7)$ & $237 \pm 14(3)$ & $247 \pm 13(5)$ & $240 \pm 2(2)$ \\
\hline
\end{tabular}

Table V. Triglyceride fatty acid content and pattern in $\omega 3-\mathrm{OO}$ and $\omega 3-\mathrm{FO}$ rats.

\begin{tabular}{|c|c|c|c|c|c|c|}
\hline & \multicolumn{6}{|c|}{ Rats (age in weeks) } \\
\hline & $\overline{\omega 3-O O}(8-9)$ & $\omega 3-\mathrm{OO}(15-16)$ & $\omega 3-\mathrm{OO}(22-23)$ & $\omega 3-F O(8-9)$ & $\omega 3-\mathrm{FO}(15-16)$ & $\omega 3-F O(22-23)$ \\
\hline Total content $(\mathrm{mg} / \mathrm{g})$ & $8.37 \pm 2.71(10)$ & $4.53 \pm 0.50(10)$ & $15.83 \pm 4.31(10)$ & $8.50 \pm 2.46(10)$ & $12.93 \pm 4.15(10)$ & $6.62 \pm 1.40(10)$ \\
\hline $\mathrm{C} 16: 0(\%)$ & $24.2 \pm 0.7(10)$ & $24.3 \pm 0.9(10)$ & $22.5 \pm 0.7(10)$ & $24.3 \pm 0.8(10)$ & $23.7 \pm 0.8(10)$ & $24.4 \pm 0.7$ (10) \\
\hline $\mathrm{C} 16: 1 \omega 7(\%)$ & $4.7 \pm 0.4(10)$ & $4.5 \pm 0.3(10)$ & $5.3 \pm 0.4(10)$ & $5.5 \pm 0.3(10)$ & $6.5 \pm 0.5(10)$ & $5.9 \pm 0.4(10)$ \\
\hline $\mathrm{C} 18: 0(\%)$ & $3.7 \pm 0.3(10)$ & $3.6 \pm 0.1(10)$ & $2.9 \pm 0.2(10)$ & $3.3 \pm 0.3(10)$ & $2.9 \pm 0.2(10)$ & $3.3 \pm 0.2(10)$ \\
\hline $\mathrm{C} 18: 1 \omega 9(\%)$ & $29.4 \pm 0.4(10)$ & $26.8 \pm 0.4(10)$ & $28.3 \pm 0.5(10)$ & $30.1 \pm 0.4(10)$ & $28.0 \pm 0.5(10)$ & $27.2 \pm 0.3(10)$ \\
\hline $\mathrm{C} 18: 2 \omega 6(\%)$ & $30.3 \pm 0.8(10)$ & $34.0 \pm 1.2(10)$ & $35.4 \pm 0.3(10)$ & $30.5 \pm 0.9(10)$ & $33.2 \pm 1.1(10)$ & $33.3 \pm 0.8(10)$ \\
\hline $\mathrm{C} 18: 3 \omega 3(\%)$ & $0.0 \pm 0.0(10)$ & $0.0 \pm 0.0(10)$ & $0.0 \pm 0.0(10)$ & $0.0 \pm 0.0(10)$ & $0.0 \pm 0.0(10)$ & $0.0 \pm 0.0(10)$ \\
\hline $\mathrm{C} 20: 4 \omega 6(\%)$ & $2.7 \pm 0.3(10)$ & $3.0 \pm 0.2(10)$ & $2.4 \pm 0.3(10)$ & $2.0 \pm 0.1(10)$ & $2.2 \pm 0.2(10)$ & $2.8 \pm 0.1(10)$ \\
\hline $\mathrm{C} 20: 5 \omega 3(\%)$ & $0.0 \pm 0.0(10)$ & $0.0 \pm 0.0(10)$ & $0.0 \pm 0.0(10)$ & $0.0 \pm 0.0(10)$ & $0.0 \pm 0.0(10)$ & $0.0 \pm 0.0(10)$ \\
\hline $\mathrm{C} 22: 4 \omega 6(\%)$ & $0.8 \pm 0.2(10)$ & $0.6 \pm 0.2(10)$ & $0.6 \pm 0.1(10)$ & $0.4 \pm 0.1(10)$ & $0.5 \pm 0.1(10)$ & $0.5 \pm 0.1(10)$ \\
\hline $\mathrm{C} 22: 5 \omega 3(\%)$ & $0.1 \pm 0.1(10)$ & $0.0 \pm 0.0(10)$ & $0.0 \pm 0.0(10)$ & $0.0 \pm 0.0(10)$ & $0.0 \pm 0.0(10)$ & $0.0 \pm 0.0(10)$ \\
\hline $\mathrm{C} 22: 6 \omega 3(\%)$ & $0.0 \pm 0.0(10)$ & $0.0 \pm 0.0(10)$ & $0.0 \pm 0.0(10)$ & $0.0 \pm 0.0(10)$ & $0.0 \pm 0.0(10)$ & $0.0 \pm 0.0(10)$ \\
\hline $\mathrm{C} 16: 1 \omega 7 / \mathrm{C} 16: 0\left(\mathrm{x} 10^{3}\right)$ & $197 \pm 20(10)$ & $184 \pm 7(10)$ & $237 \pm 23(10)$ & $230 \pm 15(10)$ & $275 \pm 19(10)$ & $241 \pm 17(10)$ \\
\hline $\mathrm{C} 18: 1 \omega 9 / \mathrm{C} 18: 0$ & $8.6 \pm 0.9(10)$ & $7.6 \pm 0.3(10)$ & $10.6 \pm 1.0(10)$ & $9.7 \pm 0.8(10)$ & $10.3 \pm 0.9(10)$ & $8.6 \pm 0.5(10)$ \\
\hline $\begin{array}{l}(\mathrm{C} 18: 0+\mathrm{C} 18: 1 \omega 9) / \\
(\mathrm{C} 16: 0+\mathrm{C} 16: 1 \omega 7)\end{array}$ & $1.15 \pm 0.02(10)$ & $1.07 \pm 0.05(10)$ & $1.47 \pm 0.03(10)$ & $1.13 \pm 0.04(10)$ & $1.33 \pm 0.02(10)$ & $1.02 \pm 0.04(10)$ \\
\hline $\mathrm{C} 20: 4 \omega 6 / \mathrm{C} 18: 2 \omega 6\left(\times 10^{3}\right)$ & $90.1 \pm 12.0(10)$ & $89.7 \pm 8.7(10)$ & $68.6 \pm 10.2(10)$ & $67.4 \pm 5.9(10)$ & $67.7 \pm 6.0(10)$ & $84.6 \pm 4.6(10)$ \\
\hline $\mathrm{C} 22: 4 \omega 6 / \mathrm{C} 20: 4 \omega 6\left(\times 10^{3}\right)$ & $366 \pm 53(7)$ & $300 \pm 23(7)$ & $248 \pm 16(9)$ & $297 \pm 16(7)$ & $257 \pm 19(8)$ & $234 \pm 11(8)$ \\
\hline
\end{tabular}

injected with a lipid emulsion and with a high total fatty acid content in triglycerides $(27.5 \pm 3.7 \mathrm{mg} / \mathrm{g}$ wet wt) contained detectable amounts of $\mathrm{C} 18: 303$ in muscle triglycerides, with a mean weight percentage in these 7 animals of $0.10 \pm 0.01$, i.e. 30 times lower than in control rats. No C20:5 23 was detected in any of the $60 \omega 3-\mathrm{OO}$ and $\omega 3$-FO rats. A sizeable amount of either $\mathrm{C} 22: 5 \mathrm{\omega} 3$ or $\mathrm{C} 22: 6 \mathrm{\omega} 3$ was only found in 5 of these 60 rats. It represented no more than $0.36 \pm 0.18 \%$ of the total fatty acid content of triglycerides, itself usually again in the high range of individual values. 
Long-chain polyunsaturated $\omega 6$ fatty acids. At variance with the findings made in phospholipids, the weight percentage of C18:2w6 in muscle triglycerides was lower in $\omega 3$-depleted rats than in control animals. It averaged $32.35 \pm 0.50 \%(\mathrm{n}=18)$ in $\omega 3$-NI rats, $33.25 \pm 0.67 \%(n=30)$ in $\omega 3-\mathrm{OO}$ rats and $32.35 \pm 0.58 \%(\mathrm{n}=30)$ in $\omega 3-\mathrm{FO}$ rats, as distinct $(\mathrm{p}<0.001)$ from $39.29 \pm 0.90 \%(n=15)$ in control animals. Likewise, the relative contribution of $\mathrm{C} 20: 4 \omega 6$ to the muscle triglycerides averaged $2.52 \pm 0.08 \%(n=78)$ in the $\omega 3$-depleted rats, as distinct $(\mathrm{p}<0.05)$ from $2.94 \pm 0.17 \%(\mathrm{n}=15)$ in control animals. Only the weight percentage of $\mathrm{C} 22: 4 \omega 6$ yielded a mean value higher, albeit not significantly so, in $\omega 3-\mathrm{NI}$ rats $(0.33 \pm 0.08 \%$; $\mathrm{n}=18)$ versus control animals $(0.22 \pm 0.07 \% ; \mathrm{n}=15)$. The weight percentage of $\mathrm{C} 22: 4 \omega 6$ was higher $(\mathrm{p}<0.05)$ in the $\omega 3$ depleted rats injected with a lipid emulsion $(0.56 \pm 0.06 \%$; $\mathrm{n}=60)$ than in $\omega 3$-NI rats and, as such, also higher $(\mathrm{p}<0.01)$ than in control animals. Of the three long-chain polyunsaturated $\omega 6$ fatty acids under consideration here, only C20:4 $\omega 6$ displayed in the $\omega 3$-depleted rats a significant agerelated change; its weight percentage averaging $2.29 \pm 0.15 \%$ $(\mathrm{n}=26)$ in 8 - to 9 -week-old rats, as distinct $(\mathrm{p}<0.05)$ from $2.63 \pm 0.09 \%(\mathrm{n}=52)$ in older animals.

The mean $\mathrm{C} 20: 4 \omega 6 / \mathrm{C} 18: 2 \omega 6$ ratio in muscle triglycerides was somewhat higher in $\omega 3$-NI rats $\left(79.0 \pm 4.8 \times 10^{-3} ; \mathrm{n}=18\right)$ than in control animals $\left(75.7 \pm 5.0 \times 10^{-3} ; \mathrm{n}=15\right)$ and, likewise, somewhat higher in $\omega 3-\mathrm{OO}$ rats $\left(82.8 \pm 6.1 \times 10^{-3} ; \mathrm{n}=30\right)$ than in $\omega 3$-FO rats $\left(73.2 \pm 3.4 \times 10^{-3} ; \mathrm{n}=30\right)$. Such differences failed, however, to achieve statistical significance. The C22:4w6/ $\mathrm{C} 20: 4 \omega 6$ ratio in muscle triglycerides was also higher $(\mathrm{p}<0.001)$ in $\omega 3$-NI rats $(0.242 \pm 0.007 ; n=10)$ or the other $\omega 3$ depleted rats than in control animals $(0.167 \pm 0.007 ; n=7)$. Likewise, it only represented, in $\omega 3-\mathrm{FO}$ rats, $87.4 \pm 3.1 \%$ $(\mathrm{n}=23 ; \mathrm{p}<0.05)$ of the mean corresponding values found at the same age in $\omega 3-\mathrm{OO}$ rats $(100.0 \pm 5.3 \% ; n=23)$. These findings suggest that the generation of long-chain polyunsaturated $\omega 6$ fatty acids from their precursors was facilitated in 13 -depleted rats; such a situation being opposed by the prior intravenous injection of the MCT:FO as compared to the MCT-OO emulsion. To note, the two ratios under consideration here displayed little age-related change in the $\omega 3$-depleted rats. In this respect, the sole consistent finding

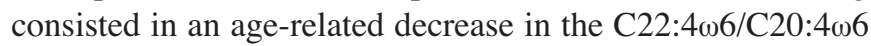
ratio in the $\omega 3$-depleted rats injected with a lipid emulsion. Relative to the overall mean values found in the same type of rats ( $\omega 3-\mathrm{OO}$ or $\omega 3-\mathrm{FO}$ rats) the results recorded in the 8- to 9-, 15- to 16- and 22- to 23-week-old rats indeed averaged, respectively, $117.8 \pm 9.8(n=14), 99.2 \pm 5.1(n=15)$ and $86.0 \pm 3.4 \%(n=17)$. The latter value was significantly different from both that recorded in the 8- to 9-week-old rats $(\mathrm{p}<0.005)$ and that found in the 15- to 16 -week-old animals $(\mathrm{p}<0.05)$.

C16 and C18 fatty acids. Apart from C18:2w6, the two most abundant fatty acids in muscle triglycerides were C16:0 and

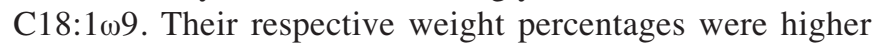
$(\mathrm{p}<0.001)$ in $\omega 3-\mathrm{NI}$ rats $(24.77 \pm 0.58$ and $28.07 \pm 0.35 ; \mathrm{n}=18)$ than in control animals $(21.40 \pm 0.47$ and $19.99 \pm 0.49 ; n=15)$. Likewise, the weight percentage of $\mathrm{C} 16: 1 \omega 7$ was higher in $\omega 3$-NI rats $(5.37 \pm 0.23 ; \mathrm{n}=18)$ than in control animals
$(3.28 \pm 0.27 ; n=15)$. Although the former value was not significantly different from that found in either the $\omega 3-\mathrm{OO}$ $(4.82 \pm 0.22 ; n=30)$ or $\omega 3$-FO rats $(5.96 \pm 0.24 ; n=30)$, the latter two percentages differed significantly $(\mathrm{p}<0.001)$ from one another.

The C16:1 $\omega 7 / \mathrm{C} 16: 0$ ratio in triglycerides was higher $(\mathrm{p}<0.001)$ in $\omega 3-\mathrm{NI}$ rats $(0.220 \pm 0.012 ; \mathrm{n}=18)$ than in control animals $(0.153 \pm 0.012 ; \mathrm{n}=15)$. It was also higher $(\mathrm{p}<0.01)$ in the $\omega 3$-FO $(0.248 \pm 0.010 ; \mathrm{n}=30)$ than in the $\omega 3$-OO rats $(0.206 \pm 0.011 ; n=30)$. As a matter of fact, it averaged in the former rats $122.5 \pm 6.0 \%(n=30 ; p<0.005)$ of the mean corresponding values found at the same age in the $\omega 3-\mathrm{OO}$ rats $(100.0 \pm 4.7 \% ; n=30)$. These findings are similar to those

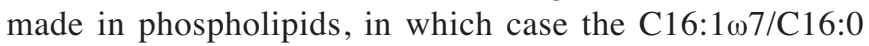
ratio was also higher in $\omega 3-\mathrm{FO}$ rats than in $\omega 3-\mathrm{OO}$ rats (see above). In the soleus muscle triglycerides, however, no significant age-related changes in the $\mathrm{C} 16: 1 \omega 7 / \mathrm{C} 16: 0$ ratio was observed in the $\omega 3$-depleted rats. The values recorded in young, middle-aged and older rats averaged, respectively, $95.4 \pm 4.8,99.1 \pm 3.9$ and $105.5 \pm 5.8 \%(n=26$ in all cases) of the overall mean values found in each type of $\omega 3$-depleted rats $(\omega 3-\mathrm{NI}, \omega 3-\mathrm{OO}$ and $\omega 3-\mathrm{FO})$. The latter three means did not differ from one another ( $\mathrm{p}>0.15$ or more). At the most, there was a trend towards an age-related increase in the C16:1 $107 /$ C16:0 ratio in the triglycerides of $\omega 3$-depleted rats, as observed in the phospholipids of the same animals.

The C18:1 $\omega 9 / \mathrm{C} 18: 0$ ratio in muscle triglycerides was also higher $(\mathrm{p}<0.001)$ in the $\omega 3-\mathrm{NI}$ rats $(8.71 \pm 0.56 ; \mathrm{n}=18)$ than in the control animals $(5.72 \pm 0.31 ; \mathrm{n}=15)$. It failed to differ significantly in $\omega 3-\mathrm{NI}, \omega 3-\mathrm{OO}(8.95 \pm 0.51 ; \mathrm{n}=30)$ and $\omega 3-\mathrm{FO}$ rats $(9.53 \pm 0.43 ; \mathrm{n}=30)$. The trend towards a higher value in the $\omega 3$-FO rats than in the other $\omega 3$-depleted animals coincides with the significant difference for the $\mathrm{C} 18: 1 \omega 9 / \mathrm{C} 18: 0$ ratio found in phospholipids, when comparing $\omega 3$-FO rats to $\omega 3$ $\mathrm{NI}$ and $\omega 3-\mathrm{OO}$ rats (see above). As also observed in muscle phospholipids, no significant age-related changes in the C18:1 $19 / \mathrm{C} 18: 0$ ratio were found in muscle triglycerides. The values recorded in 8- to 9-, 15 - to 16- and 22- to 23 -week-old rats averaged, respectively, 102.9 $\pm 5.9,95.6 \pm 4.4$ and $101.5 \pm 5.9 \%$ ( $n=26$ in all cases) of the mean corresponding overall values found in the same type of $\omega 3$-depleted rats ( $\omega 3-\mathrm{NI}, \omega 3-\mathrm{OO}$ and $\omega 3-\mathrm{FO})$. These three percentages failed to differ significantly from one another ( $\mathrm{p}>0.3$ or more).

The $(\mathrm{C} 18: 0+\mathrm{C} 18: 1 \omega 9) /(\mathrm{C} 16: 0+\mathrm{C} 16: 1 \omega 7)$ ratio in muscle triglycerides was higher $(\mathrm{p}<0.001)$ in the $\omega 3-\mathrm{NI}(1.342 \pm 0.035$; $\mathrm{n}=18)$, $\omega 3-\mathrm{OO}(1.228 \pm 0.036 ; \mathrm{n}=30)$ or $\omega 3-\mathrm{FO}$ rats $(1.160 \pm 0.031 ; \mathrm{n}=30)$ than in the control animals $(0.960 \pm 0.021$; $n=15)$. The mean values found in either $\omega 3-\mathrm{OO}$ or $\omega 3-\mathrm{FO}$ rats, which failed to differ significantly from one another, were both lower ( $<<0.05$ or less) than that recorded in $\omega 3-\mathrm{NI}$ rats. Relative to the overall mean value found in each type of $\omega 3$-depleted rats ( $\omega 3$-NI, $\omega 3-\mathrm{OO}$ and $\omega 3-\mathrm{FO})$, the same ratio increased ( $\mathrm{p}<0.025$ or less) from $93.5 \pm 1.6 \%$ in young $\omega 3$ depleted rats to $101.6 \pm 3.0$ and $104.9 \pm 3.2 \%(n=26$ in all cases) in the 15 - to 16 - and 22- to 23 -week-old $\omega 3$-depleted rats.

At this point, it should be mentioned that some of the variables under consideration in the muscle triglycerides were related to the total fatty acid content of such triglycerides. To 
cite only one example, the correlation coefficient between the $\mathrm{C} 16: 1 \omega 7 / \mathrm{C} 16: 0$ and $\mathrm{C} 18: 1 \omega 9 / \mathrm{C} 18: 0$ ratios in muscle triglycerides and the total fatty acid content of such triglycerides (logarithmic value) averaged, respectively, 0.7570 and 0.9311 ( $\mathrm{n}=18$ and $\mathrm{p}<0.001$ in both cases) in $\omega 3$ NI rats, 0.7144 and 0.8542 ( $n=30$ and $p<0.001$ in both cases) in $\omega 3$-OO rats, and 0.4405 and $0.8346(n=30$ in both cases; $\mathrm{p}<0.05$ or less) in $\omega 3-\mathrm{FO}$ rats.

\section{Discussion}

The present results deal with three interrelated issues, namely differences in muscle phospholipid and triglyceride fatty acid content and the pattern between i) control and $\omega 3$-NI rats, ii) $\omega 3$-depleted rats of increasing age, and iii) $\omega 3$-OO versus $\omega 3$ FO rats.

Concerning the first of these three issues, the major findings were as follows. The total fatty acid content of muscle phospholipids was lower in w3-depleted rats than in control animals. A comparable situation was recently found in the cardiac muscle of the same animals (9). At first glance, the fact that the product between the logarithm of the total fatty acid content of triglycerides by their C20:4 $\omega 6$ weight percentage was significantly lower in $\omega 3$-depleted rats than in control animals does not suggest the presence, in the former rats, of muscle steatosis, at variance with the presence of liver steatosis in the same animals $(3,8)$. Nevertheless, this finding indicates that, for a given total amount of triglycerides in the soleus muscle, the $\mathrm{C} 20: 4 \omega 6$ weight percentage is lower in 63 -depleted rats than in control animals. Since the content of C20:4w6 is extremely low in adipocyte lipids (3), the latter consideration supports the view that the relative contribution of adipocyte-type triglycerides to the total amount of muscle triglycerides is higher in $\omega 3$-depleted rats than in control animals (10).

In terms of the phospholipid fatty acid pattern and in addition to the expected depletion in $\omega 3$ fatty acids with low $\mathrm{C} 22: 6 \omega 3 / \mathrm{C} 22: 5 \omega 3$ ratio, and the increase in $\omega 6$ fatty acid

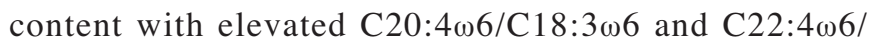
$\mathrm{C} 20: 4 \omega 6$ ratios, the $\omega 3$-depleted rats displayed increased activity of $\Delta 9$-desaturase, as judged from both the C16:1 $\omega 7 /$ C16:0 and C18:1 $19 / \mathrm{C} 18: 0$ ratios, and unchanged activity of elongase, as judged from the $(\mathrm{C} 18: 0+\mathrm{C} 18: 1 \omega 9) /(\mathrm{C} 16: 0+$ $\mathrm{C} 16: 1 \omega 7)$ ratio. Likewise, in the muscle triglycerides of $\omega 3-$ depleted rats, a depletion of long-chain polyunsaturated $\omega 3$ fatty acids and a facilitated generation of long-chain polyunsaturated $\omega 6$ fatty acids from their precursors coincided with higher $\mathrm{C} 16: 1 \omega 7 / \mathrm{C} 16: 0$ and $\mathrm{C} 18: 1 \omega 9 / \mathrm{C} 18: 0$ ratios and, in this case, an elevated $(\mathrm{C} 18: 0+\mathrm{C} 18: 1 \omega 9) /(\mathrm{C} 16: 0+\mathrm{C} 16: 1 \omega 7)$ ratio.

Several of the lipid variables displayed age-related changes in the $\omega 3$-depleted rats. Such was the case, for instance, for a progressive increase of the phospholipid content in $\mathrm{C} 22: 5 \omega 3, \mathrm{C} 22: 6 \omega 3$ and $\mathrm{C} 20: 4 \omega 6$ and phospholipid $\mathrm{C} 16: 1 \omega 7 / \mathrm{C} 16: 0$ ratio and a progressive decrease in the $\mathrm{C} 22: 4 \omega 6$ and $\mathrm{C} 22: 4 \omega 6 / \mathrm{C} 20: 4 \omega 6$ ratio in the same phospholipids. Likewise, in muscle triglycerides of $\omega 3$-depleted rats, an age-related increase in the $\mathrm{C} 20: 4 \omega 6$ content and $(\mathrm{C} 18: 0+$ $\mathrm{C} 18: 1 \omega 9) /(\mathrm{C} 16: 0+\mathrm{C} 16: 1 \omega 7)$ ratio was observed. Most of these changes shifted in the direction of the values otherwise found in control rats and, hence, could be considered as a trend towards normalization. Such is not the case, however,

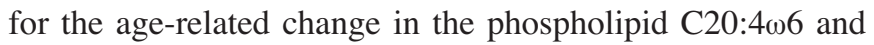

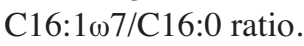

A comparable dichotomy characterized the differences between $\omega 3-\mathrm{OO}$ and $\omega 3-\mathrm{FO}$ rats. Indeed, on one hand, the increase in the phospholipid content of C22:5 23 and $\mathrm{C} 22: 6 \omega 3$ found in the latter rats, as well as the lowering of the $\mathrm{C} 20: 4 \omega 6 / \mathrm{C} 18: 2 \omega 6$ ratio found in both the phospholipids and triglycerides of $\omega 3-\mathrm{FO}$ rats and that of the C22:4 $106 /$ $\mathrm{C} 20: 4 \omega 6$ ratio in their triglycerides, can all be considered as a move towards the values otherwise found in control animals. On the other hand, however, the higher values for the

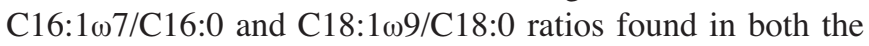
phospholipids and triglycerides of $\omega 3-\mathrm{FO}$ rats, as compared to $\omega 3-\mathrm{OO}$ rats, accentuate the difference otherwise recorded when comparing $\omega 3$-depleted rats to control animals.

The opposite directions of both age-related changes in selected lipid variables of $\omega 3$-depleted rats and those attributable to the prior injection of the MCT:FO emulsion (as distinct from the MCT:OO emulsion), i.e. the move either towards correction or accentuation of the anomalies found in $\omega 3$-depleted rats, are reminiscent of comparable findings made when considering the difference between $\omega 3-\mathrm{OO}$ and w3-FO rats in terms of the metabolism of D-glucose in stretched soleus muscle examined ex vivo (1).

In our opinion, such an analogy calls for further investigation on the possible cause-to-effect link between selected lipid variables, e.g. the activity in $\Delta 9$-desaturase and resulting $\mathrm{C} 16: 1 \omega 7 / \mathrm{C} 16: 0$ and $\mathrm{C} 18: 1 \omega 9 / \mathrm{C} 18: 0$ ratios in muscle phospholipids, and selected metabolic variables, e.g. the net rate of glycogen synthesis, which are both higher in w3-depleted rats than in control animals and both further increased in the $\omega 3-\mathrm{FO}$ rats. In the same perspective, in the $\omega 3$-deprived rats, the depletion of phospholipids in longchain polyunsaturated $\omega 3$ fatty acids and their abnormally high content in long-chain polyunsaturated $\omega 6$ fatty acids could somehow account for a low ratio between the output of ${ }^{14} \mathrm{C}$-labelled amino acids and acidic metabolites found in the soleus muscle of $\omega 3-\mathrm{OO}$ rats (as compared to control animals) exposed in vitro to $\mathrm{D}-\left[\mathrm{U}-{ }^{14} \mathrm{C}\right]$ glucose; both these lipid and metabolic defects being counteracted by the prior intravenous injection of the MCT:FO emulsion.

In conclusion, therefore, the present work draws attention to the unusual situation found in the skeletal muscle of 133 depleted rats, in which obvious dissimilarities, i.e. either normalization or aggravation, are observed when considering the changes attributable to differences in age, in terms of the fatty acid pattern of cell lipids, and those attributable to the prior intravenous injection of an $\omega 3$-rich lipid emulsion, in terms of both the fatty acid pattern and the metabolism of Dglucose in soleus muscle.

\section{Acknowledgements}

This study was supported in part by a grant from the Région de Bruxelles-Capitale (BC-BR 246/2410) to Target Hit s.a. (Brussels, Belgium). The lipid emulsions were provided by 
Braun Melsungen (Melsungen, Germany). We are grateful to J-M. Chardigny (Laboratoire de Nutrition Humaine, Université d'Auvergne, Clermont-Ferrand, France) for the supply of $\omega 3$ depleted rats, A. Chwalik and A. Dufour for their technical assistance and C. Demesmaeker for the secretarial help.

\section{References}

1. Agascioglu E, Zhang Y, Sener A, Portois L, Chardigny J-M, Malaisse WJ and Carpentier YA: Phospholipid fatty acid pattern and D-glucose metabolism in muscles from $\omega 3$ fatty aciddepleted rats. Biochimie 89: 374-382, 2007.

2. Courtois P, Louchami K, Portois L, Chardigny J-M, Sener A, Carpentier YA and Malaisse WJ: Effects of a medium-chain triglyceride:fish oil emulsion administered intravenously to $\omega 3$ fatty acid-depleted rats on cationic fluxes in aortic rings. Int $\mathrm{J}$ Mol Med 16: 1089-1093, 2005.

3. Oguzhan B, Sancho V, Acitores A, Villanueva-Peñacarrillo ML, Portois L, Chardigny J-M, Sener A, Carpentier YA and Malaisse WJ: Alteration of adipocyte metabolism in $\omega 3$ fatty acid-depleted rats. Horm Metab Res 38: 789-798, 2006.

4. Oguzhan B, Zhang Y, Louchami K, Courtois P, Portois L, Chardigny J-M, Malaisse WJ, Carpentier YA and Sener A: Pancreatic islet function in $\omega 3$ fatty acid-depleted rats. Glucose metabolism and nutrient-stimulated insulin release. Endocrine 29: 457-466, 2006.

5. Peltier S, Malaisse WJ, Portois L, Demaison L, Novel-Chate V, Chardigny J-M, Sebedio JL, Carpentier YA and Leverve XM: Acute in vivo administration of a fish oil-containing emulsion improves post-ischemic cardiac function in $\omega 3$-depleted rats. Int J Mol Med 18: 741-749, 2006.
6. Zhang Y, Oguzhan B, Louchami K, Chardigny J-M, Portois L, Carpentier YA, Malaisse WJ, Herchuelz A and Sener A: Pancreatic islet function in $\omega 3$ fatty acid-depleted rats. Alteration of calcium fluxes and calcium-dependent insulin release. Am J Physiol 291: E441-E448, 2006.

7. Richelle M, Carpentier YA and Deckelbaum RJ: Long- and medium-chain triacylglycerols in neural lipid-exchange processes with human plasma low-density lipoproteins. Biochemistry 33: 4872-4878, 1994.

8. Louchami K, Zhang Y, Oguzhan B, Carpentier YA, Genten F, Danguy A, Malaisse WJ and Sener A: Rapid changes in liver lipid composition and pancreatic $\mathrm{K}^{+}$handling and secretory behaviour provoked by the intravenous administration of a medium-chain triglyceride:fish oil emulsion to long-chain polyunsaturated $\omega 3$ fatty acid-depleted rats. Int J Mol Med 18: 1047-1055, 2006.

9. Carpentier YA, Peltier S, Portois L, Sener A and Malaisse WJ: Alteration of heart phospholipid and triglyceride content and fatty acid pattern in rats depleted in long-chain polyunsaturated $\omega 3$ fatty acids. Abstracts $28^{\text {th }}$ ESPEN Congress, 104, 2006.

10. Portois L, Agascioglu E, Zhang Y, Sener A, Chardigny J-M, Malaisse WJ and Carpentier YA: Rapid effects of the intravenous injection of a medium-chain triglyceride:fish oil emulsion on triglyceride fatty acid pattern of soleus muscle from $\omega 3$ fatty acid-depleted rats. Horm Metab Res 39: 202-206, 2007. 